\title{
Genetic analysis of leukosis incidence in United States Holstein and Jersey populations
}

\author{
E. A. Abdalla, ${ }^{* 1}$ G. J. M. Rosa, ${ }^{*}$ K. A. Weigel, $\dagger$ and T. Byrem $\ddagger$ \\ *Department of Animal Sciences, and \\ †Department of Dairy Science, University of Wisconsin, Madison 53706 \\ $\ddagger$ Antel BioSystems Inc., Lansing, MI 48909
}

\section{ABSTRACT}

Bovine leukosis (BL) is a retroviral disease caused by the bovine leukosis virus that affects only cattle. It is associated with decreased milk production and increased cull rates due to development of lymphosarcoma. The virus also affects the immune system. Infected cows display a weak response to some vaccinations. It is important to determine if the heritability of BL susceptibility is greater than zero, or if the environment is the only factor that can be used to reduce the transmission and incidence of the disease. Accordingly, the aim of this study was to estimate the heritability for BL incidence and the genetic merit of sires for leukosis resistance in Holstein and Jersey cattle. Continuous scores and binary milk ELISA results for 13,217 Holstein cows from 114 dairy herds across 16 states and 642 Jersey cows from 8 dairy herds were considered. Data were obtained from commercial testing records at Antel BioSystems (Lansing, MI). Out of the 13,859 animals tested, 38\% were found to be infected with the disease. Linear and threshold animal models were used to analyze the continuous and binary data, respectively. Results from both models were similar in terms of estimated breeding values and variance components in their respective scales. Estimates of heritability obtained with the 2 approaches were approximately $8 \%$ for both breeds, indicating a considerable genetic component underlying BL disease incidence. The correlation between the estimated breeding values from the 2 models was larger than 0.90 , and the lists of top $10 \%$ bulls selected from each model had about $80 \%$ overlap for both breeds. In summary, results indicate that a simple linear model using the continuous ELISA scores as the response variable was a reasonable approach for the genetic analysis of BL incidence in cattle. In addition, the levels of heritability found indicate that genetic selection could also be used to decrease susceptibility to bovine leukosis virus infection in Holstein and Jersey cattle.

Received February 25, 2013.

Accepted May 27, 2013.

${ }^{1}$ Corresponding author: eabdalla@wisc.edu
Further research is necessary to investigate the genetic correlations of BL with other production and reproduction traits, and to search for potential genomic regions harboring major genes affecting BL susceptibility. Key words: bovine leukosis, heritability, milk ELISA, threshold model

\section{INTRODUCTION}

Bovine leukosis $(\mathbf{B L})$ is a retroviral disease in cattle caused by the bovine leukosis virus (BLV). The disease causes a neoplastic condition of tissues that affects lymph nodes and lymphocytes, giving rise to clinical disease including bovine leukemia, lymphosarcoma, and malignant lymphoma. Bovine leukosis is a bloodborne disease, and the virus survives and transfers within lymphocytes (Ott et al., 2003); a small number of infected animals show clinical signs of the infection. The National Animal Health Monitoring System (NAHMS) reported that BLV was widely prevalent in US dairy herds and $89 \%$ of all operations had cattle seropositive for BLV (NAHMS, 1997). The report also indicated that $44 \%$ of dairy cattle in the United States were infected with BLV.

The virus can be transmitted in many different ways, including direct exposure to infected blood, saliva, semen, and milk. Kobayashi et al. (2010) studied 90 dairy farms in Japan and found that housing system, dehorning, and presence of horseflies were significantly associated with within-farm seroprevalence of BLV. However, infection rates are relatively low in utero and through ingestion of milk and colostrum from infected animals (Hopkins and DiGiacomo, 1997), although the virus may transfer from infected mothers to progeny during parturition (Nagy et al., 2007). The disease can also be spread by direct transfer of blood from one animal to another. Biting or sucking of insects may be a route of transmission, as well as several routine management practices and tools such as contaminated needles, dehorners, and ear taggers. Gouge dehorning, ear tagging, and branding can contaminate feed areas and other facilities with blood. Multiple use of the same 
needle during routine vaccinations, use of unsterilized needles, and failure to change gloves during pregnancy examination can also increase the number of BLV positive animals. In a self-contained naturally infected herd of 120 dairy cattle where reactors were not preferentially culled, the prevalence rate increased from 6.1 to $34.5 \%$ during 1976 to 1978 (Wilesmith et al., 1980). Bulls can also transmit the virus if semen contains blood or lymphocytes, and infection can occur also during natural copulation. Increasing animal density per pen increases the risk of infection (Kobayashi et al., 2010).

Bovine leukosis reduces milk production, increases death losses, and has a negative effect on the dairy cattle industry in general; BLV infection is one of many pathogens that also affect reproduction (Thurmond and Hietala, 1997; Moen et al., 1998; Bartels et al., 2006). Bovine leukosis is a disease that has important effects on the international animal industry and sale of animal products (Vanleeuwen et al., 2010). The estimated economic effect of BLV infection was $\$ 44$ million in the United States in 1987 (Thurmond, 1987), but the true cost of BLV infection may be greater than current estimates due to losses in milk production (Brenner et al., 1989; Wu et al., 1989). Decreased productivity and profitability is associated with the subclinical BLV infection (Erskine et al., 2012), and positive BL herds have been significantly associated with high infectious disease incidence, reproductive inefficiency, low milk production, and higher culling rates (Emanuelson et al., 1992). A BLV-negative cow has a longer life span, produces a total of $3.5 \%$ more milk, and has, on average, 48 fewer days open per lactation than a BLV-positive cow (Brenner et al., 1989). Advantages of negative over positive BLV animals were estimated at $488 \mathrm{~kg}$ of milk, $15 \mathrm{~kg}$ of milk fat, and $16 \mathrm{~kg}$ of milk protein per lactation (Byrem et al., 2011). Using data from 20 western states with large populations of dairy cows and $46.3 \%$ BLV prevalence, Ott et al. (2003) indicated that cows in test-positive BLV herds produced $218 \mathrm{~kg}(3 \%)$ less milk per year than cows in test-negative BLV herds. Similar estimates were reported by Emanuelson et al. (1992) with data from 14,424 herds in Sweden, in which the decline in milk production associated with BLV infection was $2.5 \%$. Even when BLV infection does not seem to affect the overall animal health, it still affects significantly the milk yield (Motton, 2002).

Some other studies used individual cow data to investigate the association between milk yield and BLV infection, and different results have been reported. The difference between test-negative and test-positive BLV herds was $3.5 \%$ per cow per year (Brenner et al., 1989); however, this percentage was $11 \%$ according to D'Angelino et al. (1998). Nationally it was estimated that BLV reduced milk production by $0.7 \%$ in 1995 and led to a loss of $\$ 285$ million for producers. Moreover, such a loss in milk production cost consumers an additional $\$ 240$ million in that year, bringing the total economic loss due to BLV infection up to $\$ 525$ million, without including any veterinary expenses associated with BLV (Ott et al., 2003). In another study, Thurmond (1987) estimated the nonmilk economic losses at $\$ 80$ million. In Michigan, reduced milk production was associated with increased BLV prevalence, and BLV affected economic status in high-producing dairy herds (Erskine et al., 2012). High disease incidence in dairy herds increases the expenses associated with milk production, and, because BL affects the immune response to some vaccinations (Yamamoto et al., 1984; Erskine et al., 2011), this might be the reason behind an association between BLV infection and incidence of other diseases.

Furthermore, restriction of exports is one of the most important economic effects of BL disease. Animals or animal products infected with BLV cannot be accepted in many countries, and large monetary losses may occur to breeders by rejecting heifers, embryos, or semen produced from their animals.

Bovine leukosis virus is not known to cause disease or even to be transmissible to humans. However, higher attention and concern was brought after discovery of the human $\mathrm{T}$ cell leukemia virus type $1(\mathbf{H T L V}-\mathbf{1})$ and the significant effect of retroviruses as human pathogens (Poiesz et al., 1980); HTLV-1 is considered to be the cause of adult T-cell leukemia (Acheson, 2007; Matsuoka and Jeang, 2007). The BLV and HTLV-1 genome sequences, as well as sequences of their proteins (amino acids), are similar enough to infer that both viruses have a common ancestor (Willems et al., 2000). In addition, some research has shown a potential link between consumption of BLV-contaminated dairy and beef and incidence of breast cancer worldwide (Rees, 2012).

Clinical signs of BL are rarely seen, and in most cases a clinical test is required to determine whether an animal is infected (Schwartz and Levy, 1994). Milk ELISA test is one of the methods used for that purpose; ELISA is an assay to detect the antibodies linked to BLV in milk or blood samples. The estimated sensitivity of milk ELISA is $98 \%$, the specificity is $100 \%$ (Jacobsen et al., 1985; Monke et al., 1992). Results of the milk ELISA test are recorded on a continuous scale and then dichotomized using a threshold of 0.1 ; animals with milk ELISA score higher than that cutoff are considered infected.

Dairy studies published in 1997 and 2007 (NAHMS, 2007, 1997) reported similar percentages for the presence of antibodies against BLV, indicating ineffective progress in reducing the prevalence of the disease. However, taking into account that different testing methods 
(AGID vs. milk ELISA) were used, it is expected that BLV prevalence has been increased considering that the ELISA test has higher sensitivity compared with the AGID test (Buzała and Dereń, 2003). Due to the unfavorable genetic correlation between milk production and many undesired traits, including diseases (Pryce et al., 1997; Rauw et al., 1998; Sandoe et al., 1999), improvements in milk production per cow may be a factor contributing to increased incidence of BL. Bovine leukosis has received some attention in the veterinary and microbiology literature, but very few genetic studies have been performed. Bovine leukosis has not been included in the breeding objectives of US dairy cattle; one reason might be that the heritability for $\mathrm{BL}$ has been estimated to be zero, as reported by Detilleux et al. (1995). That estimate, however, was based on serum samples that were taken around time of calving from 124 cows only, and using a commercial kit (Leuk-Assay B; Pitman Moore Inc., Mundelein, IL) to determine BLV infection. At any rate, it has been shown that environment and management practices are important factors in disease transmission. Nevertheless, if a genetic component associated with the disease exists, it can be exploited to decrease the susceptibility of animals to BLV.

The NAHMS indicated that current management procedures were ineffective in reducing the prevalence of BL (NAHMS, 2007). At present, no vaccine is available to prevent transmission of BLV to uninfected animals, and no treatment or cure exists for those that are infected. For the reasons stated above, any possible genetic increase in resistance to the disease would assist in alleviating the detrimental effect caused by the infection on milk production. Therefore, the objectives of this study were to investigate the heritability of $\mathrm{BL}$ incidence and estimate breeding values of Holstein and Jersey sires for BL. In addition, the analyses were performed using both the milk ELISA scores and results (diagnoses) to assess their suitability and compare their (dis)advantages. The ELISA score, as a continuous variable, was analyzed using a linear Gaussian model after log-transformation; the ELISA result (positive or negative), as a binary outcome, was analyzed using a threshold model.

\section{MATERIALS AND METHODS}

\section{Data}

Data were provided by the commercial diagnostic testing division of Antel BioSystems (Lansing, MI). Pedigree information and production records were obtained from the USDA-Agricultural Research Service Animal Improvement Programs Laboratory (Beltsville, MD). Data considered in this study included ELISA scores and ELISA results (positive or negative) for Holstein and Jersey cows. Animals were tested using 3 different milk samples and those samples were taken approximately 1 yr apart. Data used for analysis were limited to those animals that showed 3 ELISA scores with all either below or above the threshold and hence a total of 3 positive or negative results. Only herds with at least 10 cows were included in the study, so that the final data comprised ELISA scores for 13,217 US Holstein daughters of 2,679 sires in 114 herds across 16 states, and 642 US Jersey daughters of 284 sires from 8 herds (Table 1).

The final pedigree files included 41,321 and 1,832 animals for Holsteins and Jerseys, respectively. The data were recorded from 2004 to 2010, and age of cow at milk ELISA testing was between 23 and 119 mo. Because no apparent signs of the disease were observed in most cases, animals included in the study were chosen by random sampling such that both suspect and nonsuspect cows were tested. The range of milk ELISA score was -0.01 to 2.98 for Holsteins and -0.04 to 0.77 for Jerseys. Cows that had milk ELISA scores above 0.1 were considered as infected with the disease. Based on that cutoff point, $38 \%$ of the Holstein cows and $30 \%$ of the Jersey cows were positive for BLV. The milk ELISA test was evaluated against a serum ELISA test using samples drawn on the same day from 2 herds with a high prevalence of leukosis; the milk ELISA had

Table 1. Summary statistics of the data available after editing

\begin{tabular}{lcc}
\hline Description & Holstein & Jersey \\
\hline Records, no. & 13,217 & 642 \\
Sires, no. & 2,679 & 284 \\
Daughters per sire, mean no. & 5.08 & 2.26 \\
Pedigree, no. & 36,931 & 1,832 \\
Herds, no. & 114 & 8 \\
Birth year, range & $1994-2008$ & $1994-2008$ \\
Age at test, mo & $23-119$ & $23-119$ \\
Age groups & 13 & 6 \\
Milk ELISA score (range) & $-0.101-2.98$ & $-0.04-0.77$ \\
BL frequency, ${ }^{1} \%$ & 38 & 30 \\
\hline
\end{tabular}

${ }^{1} \mathrm{BL}$ frequency $=$ percentage of positive bovine leukosis virus cows. Cutoff point of (0.1) was used to obtain this percentage. 
(a)

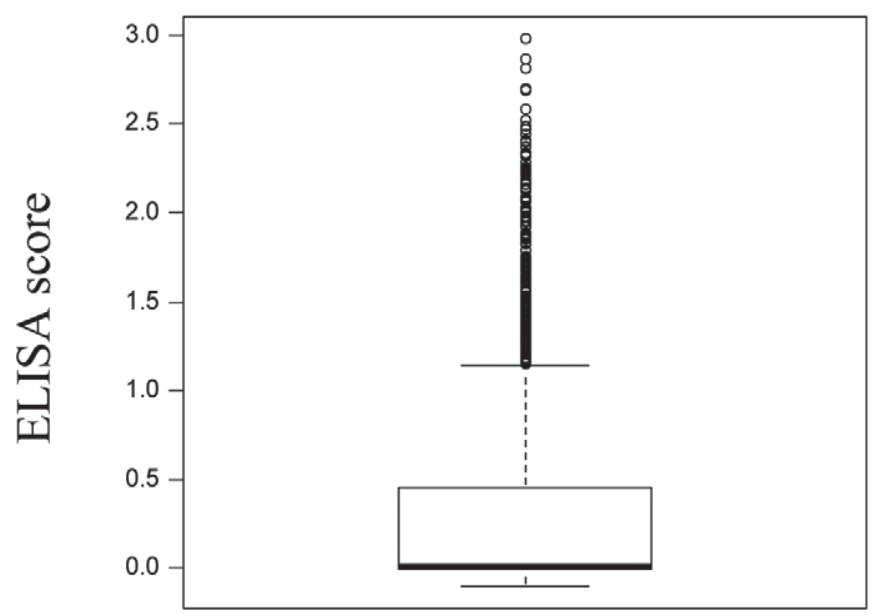

(b)

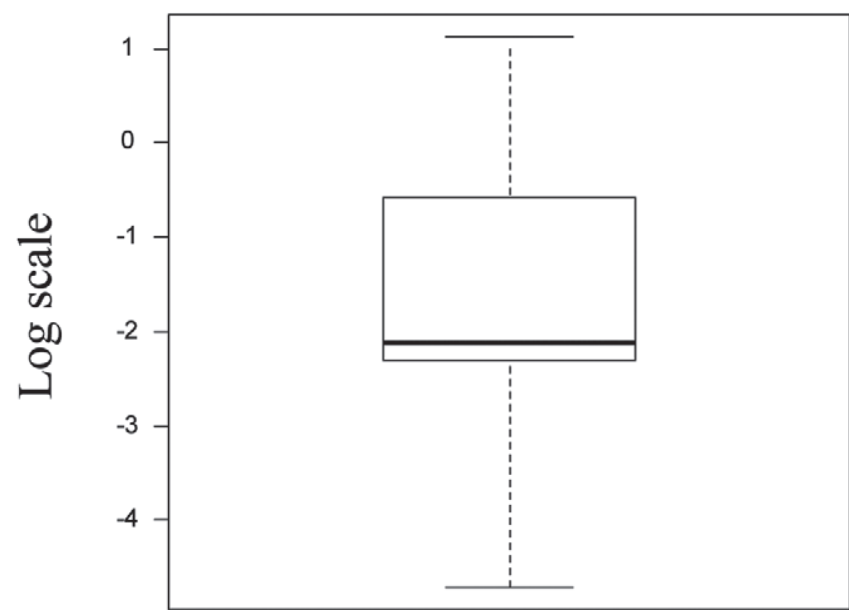

Figure 1. Box plot for Holstein ELISA scores before (a) and after (b) log-transformation. The dark line represents the median; the box around the median represents the upper and lower quartile. The dots above and below the quartiles represent outliers. The 2 horizontal lines represent the maximum and minimum values excluding outliers.

an overall agreement of $98.9 \%$ with the serum ELISA, and this value reached $100 \%$ when samples were drawn from suspect animals.

The observed ELISA score distribution was skewed to the right (Figures 1a and 2a). All analyses of ELISA scores, in its continuous scale, were then performed after a log-transformation to improve its normal approximation (Figures 2a and $2 \mathrm{~b}$ ).

\section{Models of Analysis}

The BL data available for this study included a preliminary continuous ELISA score that was measured for each cow, which was then dichotomized to a binary scale based on an arbitrary cut-off. Therefore, we used both variables (ELISA scores and ELISA diagnoses) and compared the results obtained from 2 independent analyses, one based on a linear model (after suitable data transformation) and another based on a threshold model, respectively.

Both linear and threshold models have advantages and disadvantages. The linear model, generally used in the analysis of continuous traits, is based on the assumption of normality and is simple to implement using publicly available software. However, if the assumption of Gaussian distribution of the response variable is (a)

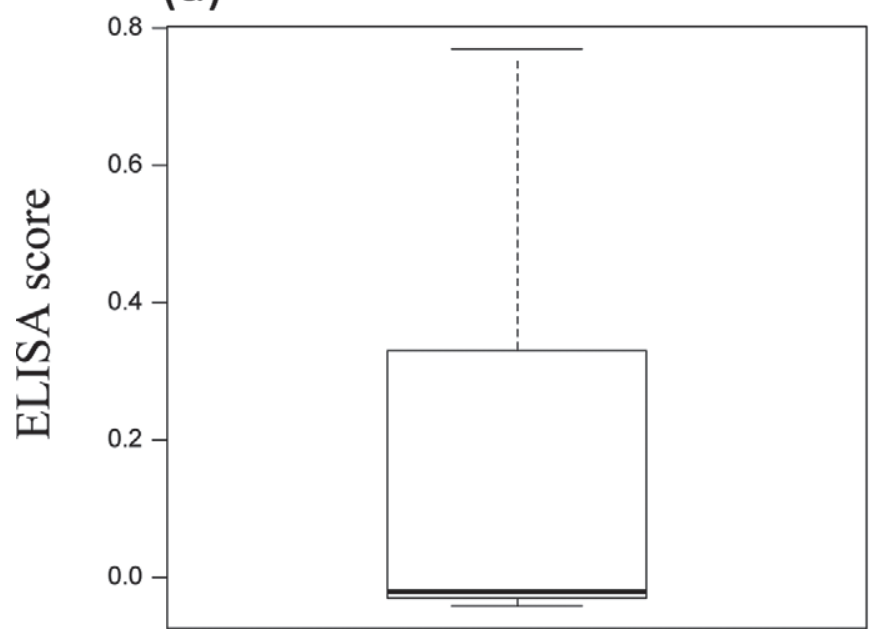

(b)

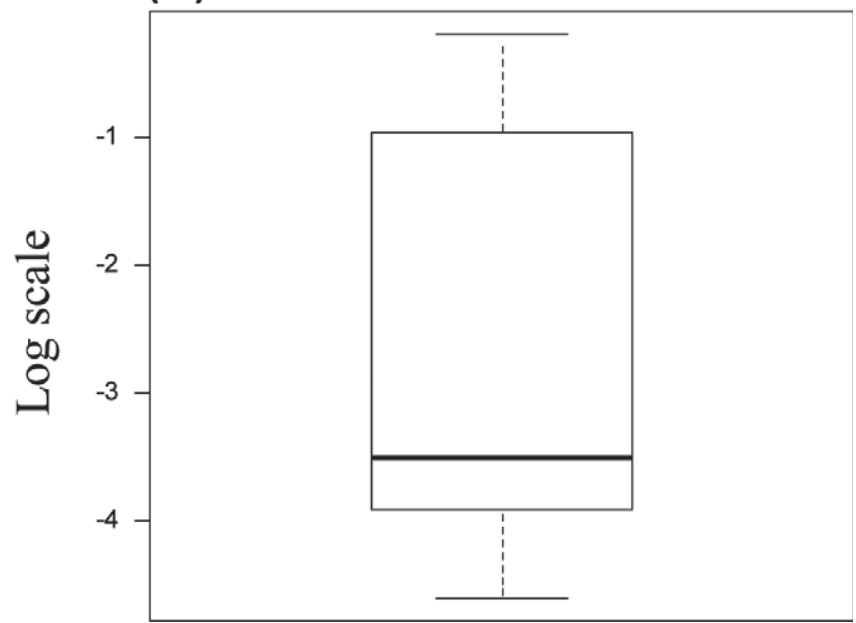

Figure 2. Box plot for Jersey ELISA scores before (a) and after log-transformation (b). The dark line represents the median; the box around the median represents the upper and lower quartile. The dots above and below the quartiles represent outliers. The 2 horizontal lines represent the maximum and minimum values excluding outliers. 
not met, for example due to skewness or the presence of outliers, results from a linear model analysis may be unreliable. Alternatives are the use of a data transformation or a more flexible modeling approach (Stranden and Gianola, 1999; Rosa et al., 2003). The threshold model, conversely, is specifically suitable for the analysis of binary traits. It is based on the assumption of a Gaussian distribution of unobservable liability values on an underling scale. The analysis on the liability scale is similar to a Gaussian linear model, but a threshold model involves an extra step that links the expectation of the binary response variable to the linear predictor describing the fixed and random factors affecting the liabilities (Wright, 1934; Gianola, 1982; Gianola and Foulley, 1983). Such a link function, also called probit, is derived from the cumulative function of a Gaussian distribution.

In some applications, for example with calving traits, a sire-maternal grandsire has been reported as advantageous relative to an animal model in terms of genetic parameters estimation (Moreno et al., 1997; Eaglen et al., 2012). However, in our study, animal and sirematernal grandsire models gave very similar results and so the animal model was used for all analyses.

The data from Holsteins and Jerseys were analyzed separately. In both models (i.e., linear and threshold), age of animal at test, year of birth, milk yield, and herd were considered as fixed effects, and additive genetic effects were considered as random variables. Some additional description of the models used and their implementation strategies are provided below.

Linear Animal Model for ELISA Score. Milk ELISA score, measured as a continuous variable, was analyzed using a linear mixed model presented in matrix notation as

$$
\mathbf{y}=\mathbf{X} \boldsymbol{\beta}+\mathbf{Z a}+\mathbf{e},
$$

where $\mathbf{y}$ is a vector of observations of milk ELISA score; $\boldsymbol{\beta}$ is a vector with the fixed effects of herd (114 levels), age at test (13 classes for Holstein and 6 classes for Jersey), year of birth (1994 to 2008), and first lactation milk yield as a continuous covariate (regression); $\mathbf{a}$ is a vector of additive genetic effects (i.e., breeding values), distributed as $\mathbf{a} \sim N\left(0, \mathbf{A} \sigma_{a}^{2}\right)$, where $\mathbf{A}$ is the numerator relationship matrix; $\mathbf{e}$ is a vector of residual effects, distributed as $\mathbf{e} \sim N\left(0, \mathbf{I} \sigma_{e}^{2}\right)$; and $\mathbf{X}$ and $\mathbf{Z}$ are incidence matrices that link individual milk ELISA scores to their respective fixed and random effects.

Threshold Model for ELISA Results. A threshold-liability model was used to analyze the binary data (Wright, 1934; Gianola, 1982; Gianola and Foulley, 1983). The threshold model assumes an underlying unobservable continuous random variable, liability $(\boldsymbol{\lambda})$, and the observed binary response takes the value 1 if $\boldsymbol{\lambda}$ is greater than a fixed threshold $(\boldsymbol{\tau})$, and 0 otherwise. Liability is assumed to be normally distributed. The residual variance $\left(\sigma_{e}^{2}\right)$ and the threshold value $(\boldsymbol{\tau})$ are not identifiable. Therefore, these parameters are set to arbitrary values (e.g., $\sigma_{e}^{2}=1$ and $\tau=0$ ). The underlying liability to BL was analyzed using a linear predictor relative to an animal model, which can be represented in matrix notation as

$$
\lambda=\mathbf{X} \boldsymbol{\beta}+\mathbf{Z} \mathbf{a}+\mathbf{e}
$$

where $\boldsymbol{\lambda}$ is a vector of unobserved liabilities of all cows, and the other effects are as for the linear model described above.

The REML and Bayesian Markov Chain Monte Carlo methods were used to estimate the variance components in the linear and the threshold models, respectively. Analyses were implemented using the programs AIREMLF90 and THRGIBBS1F90 (Misztal et al., 2002), respectively. Estimated variance components were used to obtain EBV using BLUPF90 (Misztal et al., 2002). The agreement between EBV obtained from both models was assessed through visual inspection of the scatter-plot, correlation coefficient, and overlap between lists of top 1, 5, 10, and $25 \%$ of the bulls for each model.

\section{RESULTS AND DISCUSSION}

Estimates of heritability for BL incidence in the Holstein population from the linear and threshold models were approximately $8 \%$. The heritability estimate from the liner model was slightly higher $(0.084 \pm 0.013)$ than the estimate from the threshold model $(0.081 \pm 0.016)$. A similar heritability estimate was obtained using the Jersey data with the linear model, but with higher standard error $(0.083 \pm 0.074)$. However, a lower heritability estimate was found for the Jersey data with the threshold model $(0.071 \pm 0.059)$. The higher standard error from the linear model and the lower heritability estimate from the threshold model with Jersey data are probably due to its smaller sample size. A possible bias may also exist between large and small herds due to differences in management practices, which may potentially affect estimates of genetic parameters (Phocas and Laloë, 2003). No previous studies can be used to compare these results, with the exception of a single report (Detilleux et al., 1995), which used a sample size much smaller than the sample of Jerseys in this study. Moreover, the test used to detect BLV infection in that study and the samples taken were also different 
to those used in the current study. In general, the assay used in the present study is known to provide more accurate results due to greater sensitivity and specificity.

Heritability for health traits is usually low, indicating that environment plays an important role in susceptibility to diseases. However, several studies have shown that current quantitative genetic approaches may not capture all of the genetic variance inherent in disease traits, which may contribute to the low heritability estimates (Bishop and Woolliams, 2010; Bishop et al., 2012; Lipschutz-Powell et al., 2012). Using simulated data, Lipschutz-Powell et al. (2012) found that conventional genetic models were not able to capture host genetic variation in infectivity, if present. However, indirect genetic effect models were able to capture some of that genetic variance. Many others factors may affect the estimate of disease resistance heritabilities, such as variation in exposure to the infection and disease and diagnoses tests (Bishop and Woolliams, 2010). As a result of such downward heritability estimates, potentially greater responses to selection can be obtained than those initially predicted.

The relationship between bulls' EBV obtained using ELISA scores (continuous variable) and results (binary outcome) is shown in Figure 3a. Although a linear relationship is observed between the 2 sets of estimates, some values are far from the bulk of the distribution. Ranked EBV from the 2 modeling approaches are presented in Figure 3b. By considering the number of daughters available for each sire, it is clear that sires with more daughters present higher agreement in rankings between the 2 models. Although the animal model procedure was considered as the method of choice in this study, the available data were also analyzed using a sire model approach and no significant differences were found between results from the 2 models. Sample size available for analysis might be a reason for the differences in heritability estimates between the 2 modeling approaches with the Jersey data, which gave a slightly smaller estimate with the binary ELISA results. With larger sample size and more than 4 daughters per sire, it might be expected that the 2 modeling approaches would give relatively similar estimates of heritability and ranking of sires. Jersey sires with 2 daughters or more also showed high agreement between the ranked EBV from the 2 models (Figures $4 \mathrm{a}$ and $\mathrm{b}$ ). As indicated earlier, the Jersey data set was small and most of the sires had fewer than 5 daughters. Nevertheless, if we consider that, for example, only $15 \%$ of the top bulls would be selected as breeders, it could be argued that using linear or threshold models would lead to basically the same set of bulls (overlapping more than $80 \%$ ).

For Holsteins, the overlap between the top $1 \%$ of sires from the 2 modeling approaches was $70 \%$, and this percentage increased according to the proportion of selected sires (Table 2). This trend is not surprising, because by increasing the number of the selected animals the effect of a single sire will be relatively low if it was selected by one model or both models at the same time. In terms of ranking of sires, the analysis of the Jersey data resulted in higher agreement between models than for Holstein. The percentage of agreement was $67 \%$ for the top $1 \%$ of Jersey bulls, and it rose to $94 \%$ for the top $25 \%$. The effect of the small data set available for Jersey might be the reason behind the larger increments observed in the agreement between the 2 models with increase proportion of selected sires. (a)

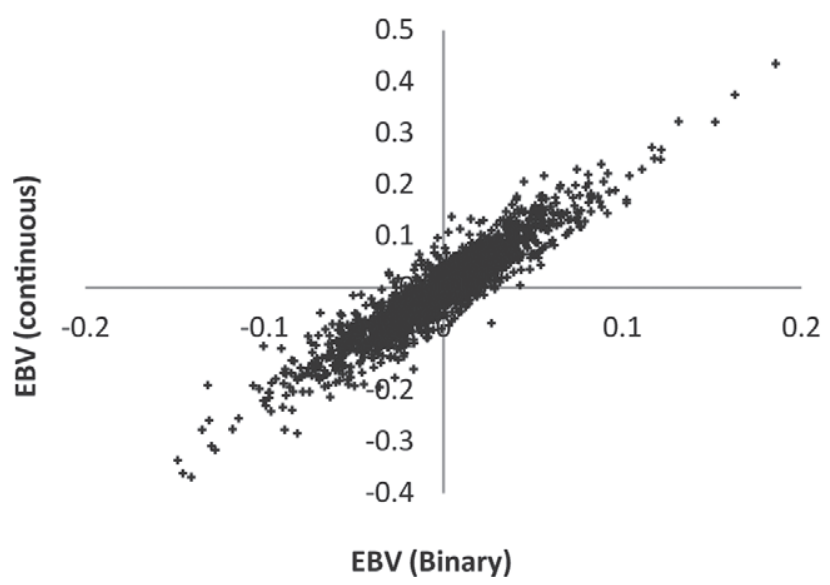

(b)

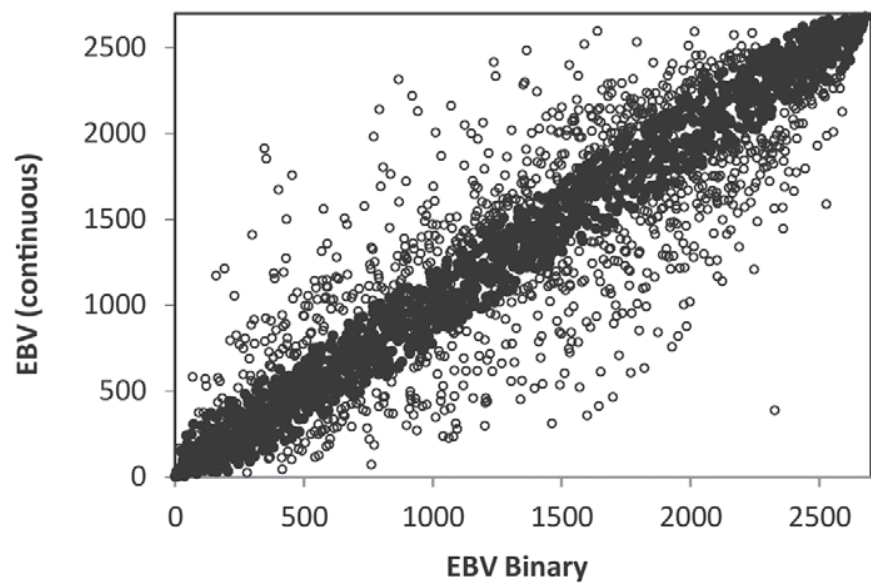

Figure 3. Relationship between EBV (a) and their ranks (b) for Holstein sires from the analyses of ELISA scores (continuous trait) and ELISA results (binary trait). Solid and open circles represent sires with $\geq 5$ and $<5$ daughters, respectively. 
(a)

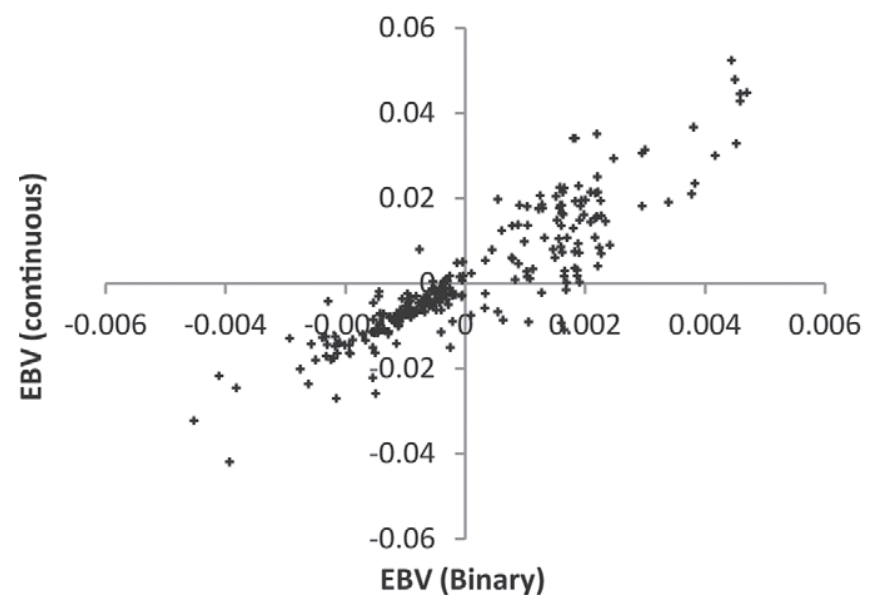

(b)

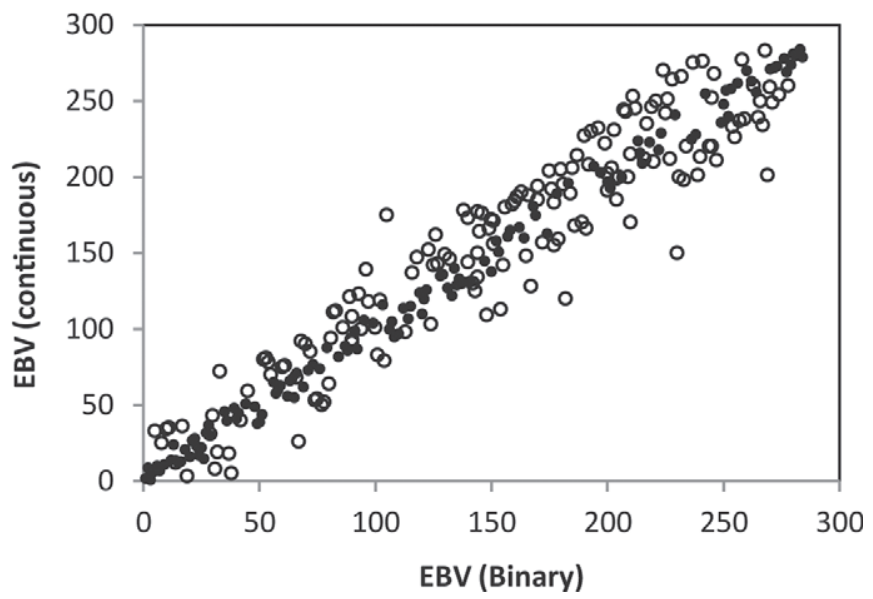

Figure 4. Relationship between EBV (a) and their ranks (b) for Jersey sires from the analyses of ELISA scores (continuous trait) and ELISA results (binary trait). Solid and open circles represent sires with $\geq 2$ and 1 single daughter, respectively.

Overall, the results suggest that ELISA scores can be a good option for the genetic analysis of the BL susceptibility, including estimation of variance components and breeding values. The advantages of a linear model over a threshold model, mainly because of its simplicity of implementation, may make it a preferred alternative.

\section{CONCLUSIONS}

For both Holsteins and Jerseys, heritability estimates for BL incidence were relatively low (i.e., around 8\%) and similar between the 2 modeling approaches. Such levels of heritability should not be neglected, as they indicate the existence of an important genetic component affecting susceptibility to BL, which could be used to genetically improve BL resistance and avoid the negative consequence of BLV infection in the dairy industry. In the case of Jerseys, the relatively small sample size may have had an effect on the observed differences between the estimates of BL heritability using the 2 models. Overall, for both breeds, sires EBV obtained from the 2 modeling approaches showed reasonable agreement, particularly for sires with more daughters. Similar results were obtained also in terms of herita-

Table 2. The proportion of agreement between the 2 modeling approaches (continuous and binary ELISA outcomes) for different percentages of selected sires for Holsteins and Jerseys

\begin{tabular}{lcccc}
\hline & \multicolumn{4}{c}{ Top } \\
\cline { 2 - 5 } Breed, \% & $1 \%$ & $5 \%$ & $10 \%$ & $25 \%$ \\
\hline Holstein & 70 & 76 & 79 & 83 \\
Jersey & 67 & 78 & 82 & 94 \\
\hline
\end{tabular}

bility estimates, suggesting that the linear model may be a preferable alternative for the genetic study of $\mathrm{BL}$ incidence, given its simplicity, availability of software, and avoidance of dichotomization of ELISA scores based on an arbitrary cutoff. In addition, by analyzing BL ELISA scores with a linear model, the potential extreme case convergence problem that may be encountered with threshold models is avoided.

\section{REFERENCES}

Acheson, N. H. 2007. Human T-cell leukemia virus type 1 fundamentals of molecular virology. Pages 294-302 in Fundamentals of Molecular Virology. John Wiley and Sons, Toronto, Canada.

Bartels, C. J., G. van Shaik, J. P. Veldhuisen, B. H. van den Borne, W. Wouda, and T. Dijkstra. 2006. Effect of Neospora caninum-serostatus on culling, reproductive performance and milk production in Dutch dairy herds with and without a history of Neospora caninum-associated abortion epidemics. Prev. Vet. Med. 77:186-198. .

Bishop, S. C., A. B. Doeschl-Wilson, and J. A. Woolliams. 2012. Uses and implications of field disease data for livestock genomic and genetics studies. Front. Genet. 3:114.

Bishop, S. C., and J. A. Woolliams. 2010. On the genetic interpretation of disease data. PLoS ONE 5:e8940.

Brenner, J., M. Vanhaam, D. Savir, and Z. Trainin. 1989. The implication of BLV infection in the productivity, reproductive capacity and survival rate of a dairy-cow. Vet. Immunol. Immunopathol. $22: 299-305$.

Buzała, E., and W. Dereń. 2003. Comparison of PLA with AGID and ELISA results in serology diagnosis of bovine leukosis. Pol. J. Vet. Sci. 6(3 Suppl.):9-11.

Byrem, T. M., R.J. Erskine, P.C. Bartlett, C. Febvay, C. Render, H.D. Norman, and J.R. Wright. 2011. Prevalence, transmission and impact of bovine leukosis in Michigan dairies. J. Dairy Sci. 94(E-Suppl. 1):15. (Abstr.)

D'Angelino, J. L., M. Garcia, and E. H. Birgel. 1998. Productive and reproductive performance in cattle infected with bovine leukosis virus. J. Dairy Res. 65:693-695.

Detilleux, J. C., M. E. Kehrli, A. E. Freeman, C. A. Whetstone, and D. H. Kelley. 1995. 2 Retroviral infections of periparturient holstein cattle-A phenotypic and genetic-study. J. Dairy Sci. 78:2294-2298. 
Eaglen, S. A., M. P. Coffey, J. A. Woolliams, and E. Wall. 2012. Evaluating alternate models to estimate genetic parameters of calving traits in United Kingdom Holstein-Friesian dairy cattle. Genet. Sel. Evol. 44:23.

Emanuelson, U., K. Scherling, and H. Pettersson. 1992. Relationships between herd bovine leukemia-virus infection status and reproduction, disease incidence, and productivity in Swedish dairy herds. Prev. Vet. Med. 12:121-131.

Erskine, R. J., P. C. Barlett, T. M. Byrem, C. L. Render, C. Febvay, and J. T. Houseman. 2012. Association between bovine leukemia virus, production, and population age in Michigan dairy herds. J. Dairy Sci. 95:727-734.

Erskine, R. J., P. C. Bartlett, K. M. Sabo, and L. M. Sordillo. 2011. Bovine leukemia virus infection in dairy cattle: Effect on serological response to immunization against j5 Escherichia coli bacterin. Vet. Med. Int. 2011:915747.

Gianola, D. 1982. Theory and analysis of threshold characters. J. Anim. Sci. 54:1079-1096.

Gianola, D., and J. L. Foulley. 1983. Sire evaluation for ordered categorical-data with a threshold-model. Genet. Sel. Evol. 15:201224

Harville, D. A., and R. W. Mee. 1984. A mixed-model procedure for analyzing ordered categorical-data. Biometrics 40:393-408.

Hopkins, S. G., and R. F. DiGiacomo. 1997. Natural transmission of bovine leukemia virus in dairy and beef cattle. Vet. Clin. North Am. Food Anim. Pract. 13:107-128.

Jacobsen, K. L., J. B. Kaneene, J. M. Miller, and R. W. Bull. 1985. Comparison of the commercial agar-gel immunodiffusion test and radioimmunoprecipitation assay for detection of antibodies to bovine leukemia-virus. Am. J. Vet. Res. 46:1430-1433.

Kobayashi, S., T. Tsutsui, T. Yamamoto, Y. Hayama, K. Kameyama, M. Konishi, and K. Murakami. 2010. Risk factors associated with within-herd transmission of bovine leukemia virus on dairy farms in Japan. BMC Vet. Res. 6:1.http://dx.doi.org/10.1186/17466148-6-1.

Lipschutz-Powell, D., J. A. Woolliams, P. Bijma, and A. B. DoeschlWilson. 2012. Indirect genetic effects and the spread of infectious disease: Are we capturing the full heritable variation underlying disease prevalence? PLoS ONE 7:e39551.

Matsuoka, M., and K.-T. Jeang. 2007. Human T-cell leukaemia virus type 1 (HTLV-1) infectivity and cellular transformation. Nat. Rev. Cancer 7:270-280.

Misztal, I., et al. 2002. BLUPF90 and related programs (BGF90), Pages 1-2 in Proc. 7th World Congr. Genet. Appl. Livest. Prod., Montpellier, France, August, 2002. Session 28. Institut National de la Recherche Agronomique (INRA), Paris, France.

Misztal, I., D. Gianola, and J. Foulley. 1989. Computing aspects of a nonlinear method of sire evaluation for categorical data. J. Dairy Sci. 72:1557-1568.

Moen, A. R., W. Wouda, M. F. Mul, E. A. M. Graat, and T. van Werven. 1998. Increased risk of abortion following Neospora caninum abortion outbreaks: A retrospective and prospective cohort study in four dairy herds. Theriogenology 49:1301-1309.

Monke, D. R., R. F. Rohde, W. D. Hueston, and R. J. Milburn. 1992. Estimation of the sensitivity and specificity of the agar-gel immunodiffusion test for bovine leukemia-virus-1,296 cases (19821989). J. Am. Vet. Med. Assoc. 200:2001-2004.

Moreno, C., D. Sorensen, L. García-Cortés, L. Varona, and J. Altarriba. 1997. On biased inferences about variance components in the binary threshold model. Genet. Sel. Evol. 29:145-160.

Motton, D. D. 2002. Bovine leukosis virus alters growth properties and casein synthesis in mammary epithelial cells. Thesis. University of California, Berkeley.

Nagy, D. W., J. W. Tyler, and S. B. Kleiboeker. 2007. Decreased periparturient transmission of bovine leukosis virus in colostrum-fed calves. J. Vet. Intern. Med. 21:1104-1107.
NAHMS. 1997. High Prevalence of BLV in U.S. Dairy Herds. USDA:APHIS:VS, CEAH, National Animal Health Monitoring System, Fort Collins, CO.

NAHMS. 2007. Bovine Leukosis Virus (BLV) on U.S. Dairy Operations. USDA:APHIS:VS, CEAH, National Animal Health Monitoring System, Fort Collins, CO.

Ott, S. L., R. Johnson, and S. J. Wells. 2003. Association between bovine-leukosis virus seroprevalence and herd-level productivity on US dairy farms. Prev. Vet. Med. 61:249-262.

Phocas, F., and D. Laloë. 2003. Evaluation models and genetic parameters for calving difficulty in beef cattle. J. Anim. Sci. 81:933-938.

Poiesz, B. J., F. W. Ruscetti, A. F. Gazdar, P. A. Bunn, J. D. Minna, and R. C. Gallo. 1980. Detection and isolation of type-C retrovirus particles from fresh and cultured lymphocytes of a patient with cutaneous T-cell lymphoma. Proc. Natl. Acad. Sci. USA 77:7415-7419.

Pryce, J. E., R. F. Veerkamp, R. Thompson, W. G. Hill, and G. Simm. 1997. Genetic aspects of common health disorders and measures of fertility in Holstein Friesian dairy cattle. Anim. Sci. 65:353-360.

Rauw, W. M., E. Kanis, E. N. Noordhuizen-Stassen, and F. J. Grommers. 1998. Undesirable side effects of selection for high production efficiency in farm animals: A review. Livest. Prod. Sci. 56:15-33.

Rees, R. K. 2012. Development of an enzyme-linked immunosorbent assay to determine the seroprevalence of bovine leukemia virus antibodies in humans. PhD Thesis. University of California., Berkeley.

Rosa, G. J. M., C. R. Padovani, and D. Gianola. 2003. Robust linear mixed models with normal/independent distributions and Bayesian MCMC implementation. Biom. J. 45:573-590.

Sandoe, P., B. L. Nielsen, L. G. Christensen, and P. Sorensen. 1999. Staying good while playing God-The ethics of breeding farm animals. Anim. Welf. 8:313-328.

Schwartz, I., and D. Levy. 1994. Pathobiology of bovine leukemiavirus. Vet. Res. 25:521-536.

Stranden, I., and D. Gianola. 1999. Mixed effects linear models with t-distributions for quantitative genetic analysis: A Bayesian approach. Genet. Sel. Evol. 31:25-42.

Thurmond, M. C. 1987. Economics of enzootic bovine leukosis. Pages 71-84 in Enzootic Bovine Leukosis and Bovine Leukemia Virus. Springer, New York, NY.

Thurmond, M. C., and S. K. Hietala. 1997. Effect of congenitally acquired Neospora caninum infection on risk of abortion and subsequent abortions in dairy cattle. Am. J. Vet. Res. 58:1381-1385.

Vanleeuwen, J. A., J. P. Haddad, I. R. Dohoo, G. P. Keefe, A. Tiwari, and R. Tremblay. 2010. Associations between reproductive performance and seropositivity for bovine leukemia virus, bovine viraldiarrhea virus, Mycobacterium avium subspecies paratuberculosis, and Neospora caninum in Canadian dairy cows. Prev. Vet. Med. 94:54-64.

Wilesmith, J. W., O. C. Straub, and R. J. Lorenz. 1980. Some observations on the epidemiology of bovine leucosis virus infection in a large dairy herd. Res. Vet. Sci. 28:10-16.

Willems, L., A. Burny, D. Collete, O. Dangoisse, F. Dequiedt, J. S. Gatot, P. Kerkhofs, L. Lefèbvre, C. Merezak, T. Peremans, D. Portetelle, J. C. Twizere, and R. Kettmann. 2000. Genetic determinants of bovine leukemia virus pathogenesis. AIDS Res. Hum. Retroviruses 16:1787-1795.

Wright, S. 1934. An analysis of variability in number of digits in an inbred strain of guinea pigs. Genetics 19:506-536.

Wu, M. C., R. D. Shanks, and H. A. Lewin. 1989. Milk and fat production in dairy cattle influenced by advanced subclinical bovine leukemia virus infection. Proc. Natl. Acad. Sci. USA 86:993-996.

Yamamoto, S., M. Onuma, H. Kodama, T. Mikami, and H. Izawa. 1984. Suppression of natural cytotoxic activity of lymphocytes from cattle and sheep during the progress of bovine leukosis. Vet. Microbiol. 9:105-111. 